\title{
Optimization Hydro-Thermal-Wind-PV Solar Using MOPSO Algorithm Applied to Economic/ Environmental Dispatch
}

\author{
Ismail Marouani*1, Chefai Dhifaoui ${ }^{2}$ and Hsan Hadj Abdallah ${ }^{3}$ \\ ${ }^{1,2,3}$ Control \& Energies Management (CEM-Lab) National Engineering School of Sfax, ENIS Sfax, Tunisia
}

\section{ABSTRACT}

The purpose in this present work exposure the application of MOPSO multiple- objective particle swarm optimization algorithm to solver dynamic economic emission dispatch problems with ramp rate. The proposed MOPSO algorithm is applied in economic emission dispatch to fin the best solutions of hydro plant, thermal units, wind and PV solar generation scheduling powers and then calculate the cost, emission functions for SOx and NOx gas pollution, and combined the three function. The dynamic economic emission distribution (DEED) is an important subject in electrical power systems network. This consists of a valve point effect(VPE), transmission powers losses, a load, an equilibration power system and generator constraints. The proposed algorithm was exanimate on ten unit test power systems. All simulations results are thorough on the MATLAB-Simulinck space.

KEY WORDS: ECONOMIC EMISSION DISPATCH PROBLEM; RAMP RATE; SOLAR POWER; ENERGY STORAGE; WIND POWER; HYDRO PLANT; MOPSO; POWER SYSTEMS; TRANSMISSION LOSSES; VALVE POINT EFFECT.

\section{INTRODUCTION}

The role of best optimal dispatch production scheduling of a thermal-renewable power system of generation pointing modest economic and minimization of emission as a benefits is necessary actually in order to swelling the demanded power generation, escalating the total fuel price and high pollution rate. Optimization scheduling of power plant production is of large importance to electric interest systems. With the low misfit cost of power hydroelectric, the problem of minimizing the transition cost of a hydrothermal system basically reduces to that of minimize the fuel cost for thermal plants user the divers constraints on the hydraulic and power system grid.

Biosc Biotech Res Comm P-ISSN: 0974-6455 E-ISSN: 2321-4007

\section{crossef}

Identifiers and Pagination

Year: 2021 Vol: 14 No (5) Special Issue

Pages: 118-125

This is an open access article under Creative

Commons License Attribn 4.0 Intl (CC-BY).

DOI: $h t t p: / / d x$.doi.org/10.21786/bbrc/14.5/23

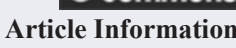

Received: $18^{\text {th }}$ Jan 2021

Accepted after revision: $29^{\text {th }}$ Mar 2021
A coal-fired power plant releases tons of ash, tons of toxic heavy metals, arsenic, mercury, cadmium, uranium, tons of thorium, soot and fine particles that escape to the atmosphere each year. Tons of $\mathrm{CO} 2$ and tons of nitrogen oxide (NOX). Thus, everyone is currently oriented towards the use of renewable energies by the integration of these different forms in electrical networks. Electricity production is responsible for 35\% of CO2 emissions linked to human activity worldwide. Fortunately, renewable energies, or green energies, have experienced a real boom since the 2000s. These new energy production sectors should in future represent a greater share of use because of the environmental impact of renewable energy.

The Clean Air Act 1990 aims to reduce greenhouse gases and acid rain. It requires that fossil fuel power plants must decrease its (NOx) emission level and (SO2) quantity. Though these approach previous have obtain simultaneously emission and total fuel cost, the scheduling problem is ultimately optimization problem of single objective both inevitable flaws. The results of optimization are critical to the balances which are difficult to be resolved. The Pareto best group cannot be acquired in one test by using different metering. To overcome the disadvantages mentioned above, many 
authors have developed strength pareto evolutionary algorithm-2 (SPEA 2) and non-dominated sorting genetic algorithm-II.

Formulation of Problem: NOx emission, SOx emission and cost of generation represent the optimized objective functions simultaneously for EED problem of windsolar-hydro-thermal plants system. while respecting the constraints of the system. The objectives functions and constraints problem given into account in the problem of formulation.

\subsection{0bjectives}

2.1.1. Cost function: Economic dispatch, or modest economic dispatch is to research the generation power that given the minimum of total fuel cost respecting constraints necessary of the system. In comparison of the hydroelectric power station cost, the operating cost of a wind- solar -hydro-thermal system is reduced specially to that of the cost of total fuel cost for thermal power plants with the cost of the PV solar power system and wind power generation units and the PV solar power system. The following expression of total fuel cost is.

$F_{u}=\sum_{t=1}^{T}\left\{\sum_{g=1}^{N g}\left[f_{g, t}\left(P_{g, t}\right)\right]+\sum_{k=1}^{N w} K_{w, k} * P_{w, k, t}+\sum_{m=1}^{N_{P V}} K_{P V, m} * P_{P V, m, t}\right\}$

Equation (2) give The expression of the total fuel cost for thermal plant, taking into count the valve-point effect( VPE).

$$
f_{g, t}\left(P_{g, t}\right)=a_{g}+b_{g} P_{g, t}+c_{g} P_{g, t}^{2}+\mid d_{g} \times \sin \left[e_{g} \times\left(P_{g}^{\min }-P_{g}\right) \mid\right.
$$

2.1.2. NOx emission function: In reference, the NOx emissions is given by the following equation:

$E_{N O_{X}}=\sum_{t=1}^{T} \sum_{g=1}^{N g}\left[\alpha_{n g}+\beta_{n g} P_{g, t}+\gamma_{n g} P_{g, t}^{2}\right]$

2.1.3.Sox emission function: The equation (4) that represent the expression of SOx emission is given by:

$$
E_{S O_{X}}=\sum_{t=1}^{T} \sum_{g=1}^{N g}\left[\alpha_{s g}+\beta_{s g} P_{g, t}+\gamma_{s g} P_{g, t}^{2}\right]
$$

2.2. Constraints of the problem: Depending on the size of the electrical network, in other words its complexity, the study of the switching of units can be conditioned by several constraints. In fact, in this context two constraints to be respected the spinning reserve constraints and demanded power of load.

\section{- Generating unit ramp-rate limits}

Violation of unit ramp rates will shorten the life for power production facilities. Thus, the ramp rate limits must be schown when the power demanded for variation of electric charge changes.

$$
\left.\begin{array}{l}
P_{g, t}-P_{g, t-1} \leq U R_{g} \\
P_{g, t-1}-P_{g, t} \leq D R_{g}
\end{array}\right\} \text { For } g \in N_{g} \text { et } t=2,3, \ldots . I
$$

If unit ramp speed limits are considered into account, actual generated power limits (5) can be obtain the variation as equation (6):

$$
\max \left(P_{g}^{\min }, P_{g, t-1}-D R_{g}\right) \leq P_{g, t} \leq \min \left(P_{g} \max _{, P_{g, t}-1}+U R_{g}\right)
$$

- Real power balance equation:

$\sum_{t=1}^{I=24}\left[\sum_{g=1}^{N_{g}} P_{g, t}+\sum_{j=1}^{N_{h}} P_{h, j, t}+\sum_{m=1}^{N_{P V}} P_{P V, m, t}+\sum_{k=1}^{N w} P_{w, k, t}+P_{b a t, t}\right]=P_{D t}+P L_{t}$

Or the total power losses of the transmission line PLt can be calculated by using B-coefficient stated as equation number (8).

$$
P_{L t}=\sum_{t=1}^{T} \sum_{g=1}^{N} P_{g, t} B_{g j} P_{j, t} ; t=1,2, \ldots, T
$$

The hydroelectric generation is a function of reservoir and discharge water rate given by the following expression:

$$
\begin{aligned}
& P_{h, j, t}=C C_{1, j}{ }^{2}{ }_{h, j, t}^{2}+C{ }_{2, j} Q_{h, j, t}^{2}+C \underset{3, j}{V}{ }_{h, j, t} \\
& \text { For }+\underset{h, j, t}{C} \underset{4, j}{V} h, j, t+C \underset{5, j}{Q} \underset{h, j, t}{Q}+{ }_{6, j} \\
& j \in N_{h, t} \text { et } t=1,2, \ldots . I
\end{aligned}
$$

For the output of power for the kth generated power of wind unit for given speed and time thas the following expression:

$$
P_{w i n}= \begin{cases}0, & \text { for } v w i n, t \leq v_{\text {in }} \text { and } v w i n, t>v_{0} \\ p r\left(\frac{v_{\text {win }, t}-v_{\text {in }}}{v_{r}-v_{\text {in }}}\right) & \text { for } v_{\text {in }} \leq v w i n, t \leq v_{r} \\ p r, & \text { for } v_{r} \leq v w i n, t \leq v_{0}\end{cases}
$$

The output power [12] from PV cell has the following equation.

$$
P_{P V m, t}(G)=\left\{\begin{array}{l}
P_{S}\left(\frac{G^{2}}{G_{s t d} \cdot R_{C}}\right) \text { for } 0<G<R_{C} \\
P_{S}\left(\frac{G}{G_{s t d}}\right) \text { for } G>R_{C}
\end{array}\right.
$$

- Real power generation limit 


$$
\begin{aligned}
& P_{g}^{\mathrm{m} \mathrm{in}} \leq P_{g, t} \leq P_{g}^{\mathrm{max}} ; F \text { or } g \in N_{g}, t \in T \\
& P_{h, j}^{\mathrm{m} \mathrm{in}} \leq P_{h, j, t} \leq P_{h, t}^{\mathrm{m} a x} ; F \text { or } j \in N_{h}, t \in T \\
& P_{w, k}^{\mathrm{m} \mathrm{in}} \leq P_{w, k, t} \leq P_{w, k}^{\max } ; \text { For } j \in N_{w}, t \in T
\end{aligned}
$$

- Constraints of Hydraulic system: All constraints of the hydraulic equipment include equations of the water balance for each hydroelectric unit in addition to the limits on the storage and rejection targets of the reservoirs :

- Physical limitations on reservoir storage volumes and discharge rates,

$$
\begin{aligned}
& V_{h, j}^{\min } \leq V_{h, j, t} \leq V_{h, j}^{\max } ; j \in N_{h}, t \in T \\
& Q{\underset{h}{\mathrm{~m}, j}}_{\mathrm{in}} \leq Q h, j, t \leq Q \mathrm{~m}_{h, j}^{\mathrm{ax}} ; j \in N_{h}, t \in T
\end{aligned}
$$

-hydro reservoir system has the following equation of continuity:

$$
\begin{aligned}
V_{h, j,(t+1)=} & V_{h, j, t}+I_{h, j, t}-Q_{h, j, t}-s_{h, j, t} \\
& R_{u j} \\
& +\sum_{l=1}\left(Q_{h l}\left(t-\tau_{l j}\right)+s_{h l}\left(t-\tau_{l j}\right)\right) ; j \in N_{h}, t \in T
\end{aligned}
$$

- $\quad$ Energy storage system ESS

Equation (16) represent The maximum discharge and charge and battery capacity :

$$
-P_{b}^{\max } \leq P_{b t} \leq P_{b}^{\min }
$$

$\mathrm{Pbt}$ : positive in discharging $\mathrm{P}^{\mathrm{d}}$.

$\mathrm{Pbt}$ : negative in charging $\mathrm{P}^{\mathrm{c}}$.

* If the ESS is charging $(\mathrm{Pb}(\mathrm{t})<0)$

* If the ESS is discharging $(\mathrm{Pb}(\mathrm{t})>0)$

* If the ESS is idle $(\mathrm{Pb}(\mathrm{t})=0)$

Multi-Objective Function: The formulation of optimization in this case of multi-objective function CDEED dispatch is given by equation (17).

$$
\operatorname{Min} F\left(P_{g i, t}\right)=\left[F u\left(P_{g, t}\right), E N O_{X}\left(P_{g, t}\right), E_{S} O_{X}\left(P_{g, t}\right)\right]
$$

Determine the optimal dispatch of active energy production which give the minimization of two contradictory objectives functions of total fuel cost and emissions quantity while srespecting several equality and inequality constraints. The CDEED is considered as an optimization of a single objective function using the weighting method as:

$\operatorname{Min} F=w F u+(1-w)\left(p f_{N O_{X}} \cdot E_{N O_{X}}+p f_{S O_{X}} \cdot E_{S O_{X}}\right)$

Where pf is the price penalty factor is as flows:

$p f_{i_{N O_{X}}}\left(P_{i g}^{\max }\right)=\frac{F u_{g, t}\left(P_{i g}^{m a x}\right)}{E_{N O_{X}}\left(P_{i g}^{m a x}\right)} s /$ ton

$$
p f_{S O_{X}}\left(P_{i g}^{\max }\right)=\frac{F u_{g, t}\left(P_{i g}^{\max }\right)}{E_{S O_{X}}\left(P_{i g}^{\max }\right)} \text { / ton }
$$

Where $0 \leq \mathrm{w} \leq 1$ is the weighting factor.

If $\mathrm{w}=1$, minimizing only the cost.

If $\mathrm{w}=0$, minimizing only the emission.

If $\mathrm{w}=0.5$ minimizing simultaneously the economic and emission.

\section{Mopso Approach}

4.1. Overview: Several scientific researches use a lot of times Particle swarm optimization and consider them as very efficient and robust methods which can be applied or used for nonlinear optimization problems and more particularly for electrical systems. In fact, these algorithms ignore several conditions such as differentiability and continuity, whether for the objective functions to be optimized or these constraints to be respected. This algorithm is introduced by Eberhart and Kennedy as an optimization tool for non-linear optimization problems.

4.2. MOPSO Algorithm: It is at random, the initialization of all the particles in the research space for the MOPSO approach. A position and velocity are assigned For each particle in the decision research space. The proposed MOPSO approach is well detailed with these different steps in the reference.

4.3. Front pareto and best compromise solution: Decision maker (DM) can assume vague or imprecise objectives for each objective function. Fuzzy sets are defined by equations called functions of membership. The DM is able to give the best evaluation for the function of membership , $\mu$ Fk subjectively and is defined as strictly monotonically with decrease and continuity function has the following expression: 


$$
\mu_{F_{k}}(i)= \begin{cases}0 & , \text { Otherwise } \\ \frac{F_{k}{ }^{M a x}-F_{k}(i)}{F_{k}{ }^{M a x}-F_{k}{ }^{\min }}, F_{k} M_{a x} \leq F_{k}(i) \leq F_{k}\end{cases}
$$

The procedure is as follows:

$$
F 2=M \text { in } E_{m_{i t}}\left(P_{g i, t}\right) \leq \varepsilon
$$

The $\varepsilon$ value will be varied from F2Max to F2min and then F1 (cost function) is minimized. The final solution using (DM) can then be found as:

$$
\begin{array}{r}
\mathrm{M} \text { ax } \\
1: n S
\end{array}\left(\begin{array}{c}
\mathrm{m} \operatorname{in}\left(\mu \mathrm{F}_{\mathrm{k}}\right) \\
1: n F
\end{array}\right)
$$

Where $\mathrm{nS}$ number of total solution and $\mathrm{nF}$ number of objective functions.

Analysis and Discussion of Results: In this paper, four cases are considered to demonstrate the performance of the proposed method such as:

Case 1: Economic dispatch.

Case 2: NOx emission dispatch.

Case 3: SOx emission dispatch.

Case 4: Combined economic emission dispatch.

Figure 1: Evolution convergence case 1 (a), case 2 (b), case 3 (c) and case 4 (d)
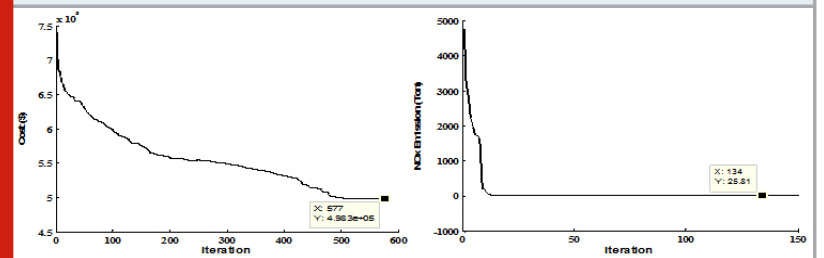

(b)

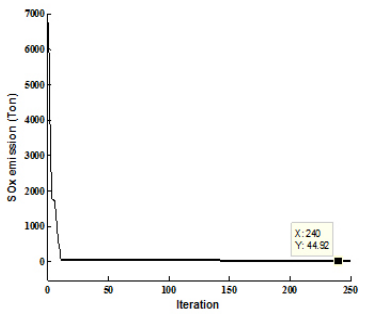

(c)

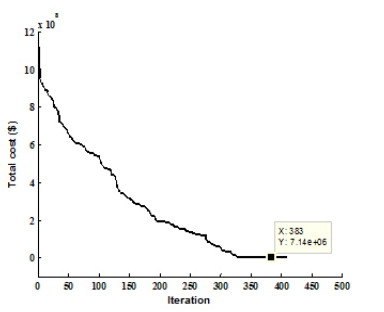

(d)

All results of simulations are obtained in MATLABsimulinck R2013a using i3-2310M CPU @ 2.10 GHz. This proposed method is applied with size of population as 200 . 600 is the number maximum of iteration. The system power data for all cases are given from. Four reservoir hydroelectric power plants are considered in this system, three thermal plants, equivalent power of wind generation unit, an equivalent PV solar power plant and an equivalent battery energy storage. A 24 intervals by day is the planning period. The valve point effect loading (VPEL) is considered into count. Hydrothermal parameters are more detailed in reference.

Figure 2: Pareto front and best solution case 1 (a), case 2 (b), case 3 (c) and case 4 (d)
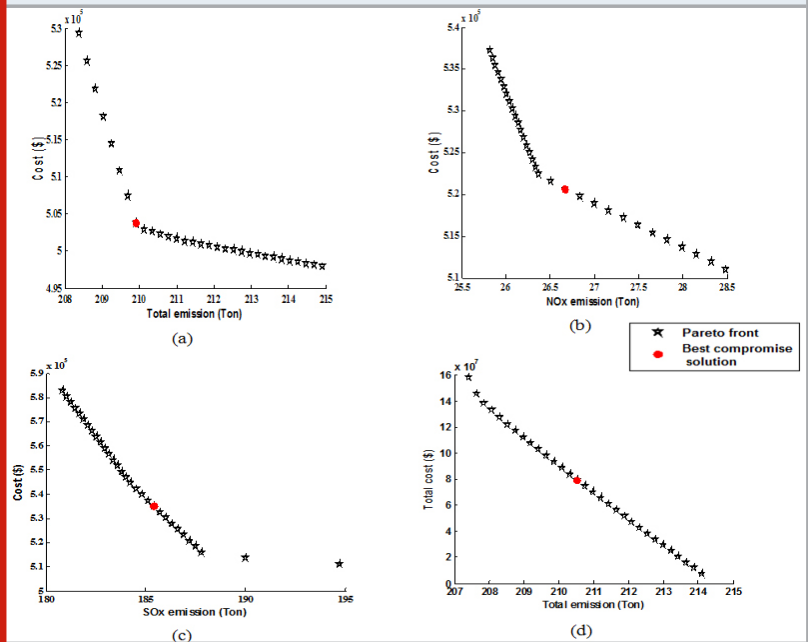

Figure 3: Hydro plant discharges $(104 \mathrm{~m} 3)$ case 1 (a), case 2 (b), case 3 (c) and case 4 (d)

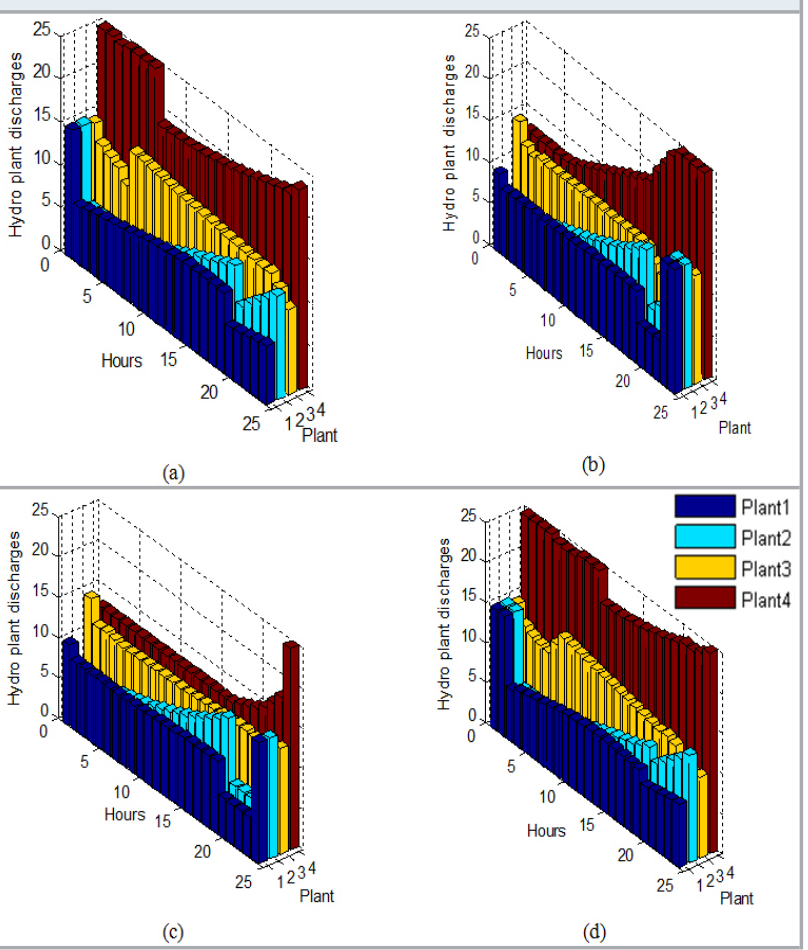

Sox and NOx coefficients are given in. The rating of wind power generator is $\mathrm{pr}=150 \mathrm{MW}$. The cut-in, cutout and rated wind speeds are vin $=4 \mathrm{~m} / \mathrm{s}, \mathrm{vo}=25 \mathrm{~m} / \mathrm{s}$ and $\mathrm{vr}=15 \mathrm{~m} / \mathrm{s}$ respectively. The direct cost coefficient Kwin for the wind power generator is taken 3.25. The rating of solar PV generator is PS=150 MW. The direct cost coefficient Kpv for the solar PV generator is taken 3.5. 
The solar radiation in the standard environment Gstd and a certain radiation point Rc are taken as $1000 \mathrm{~W} /$ $\mathrm{m} 2$ and $150 \mathrm{~W} / \mathrm{m} 2$. The forecasted wind velocity and solar radiation are taken from.

Figure 4: Hydro reservoir storage volumes (104m3) from case 1 (a), case 2 (b), case 3 (c) and case 4 (d)

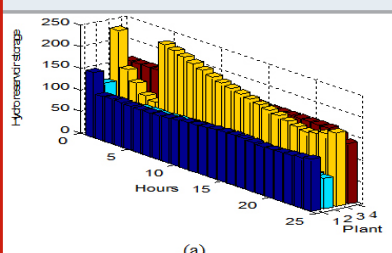

(a)

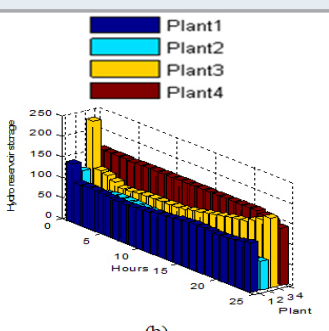

(b)

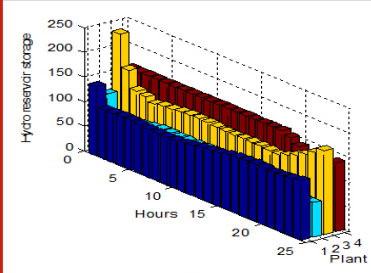

(c)

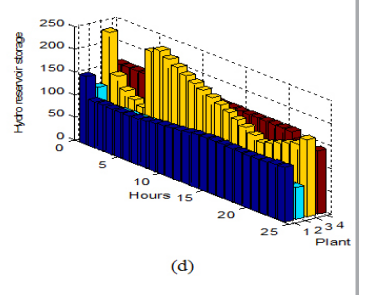

Figure 5: The ramp up/ramp down values of case 1 (a), case 2 (b), case 3 (c) and case 4 (d)
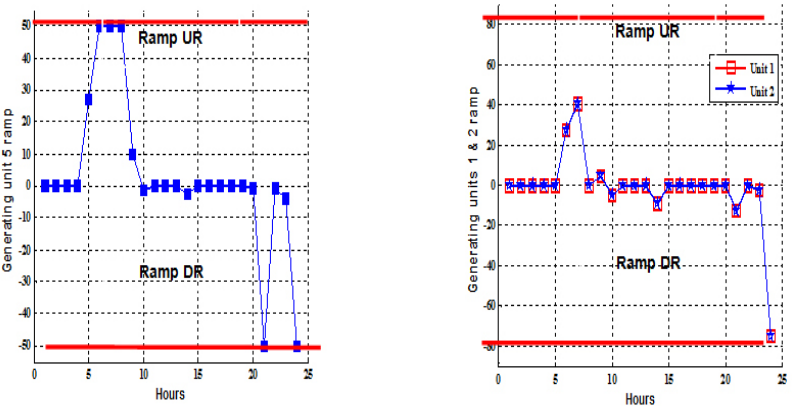

(b)
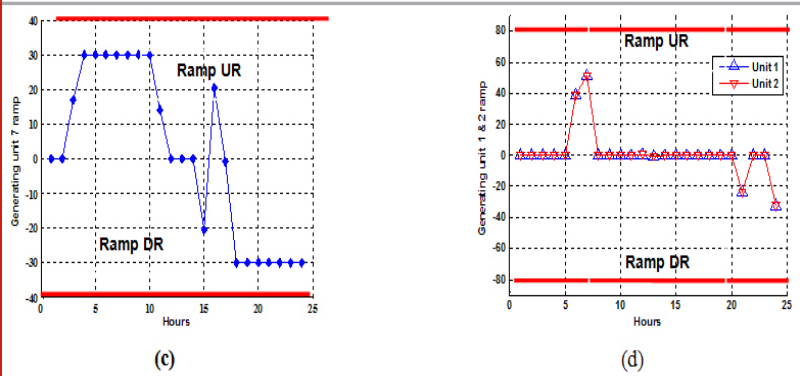

(d)

Table 1. Best scheduling and dispatching of generation (MW) for case 1 of test system

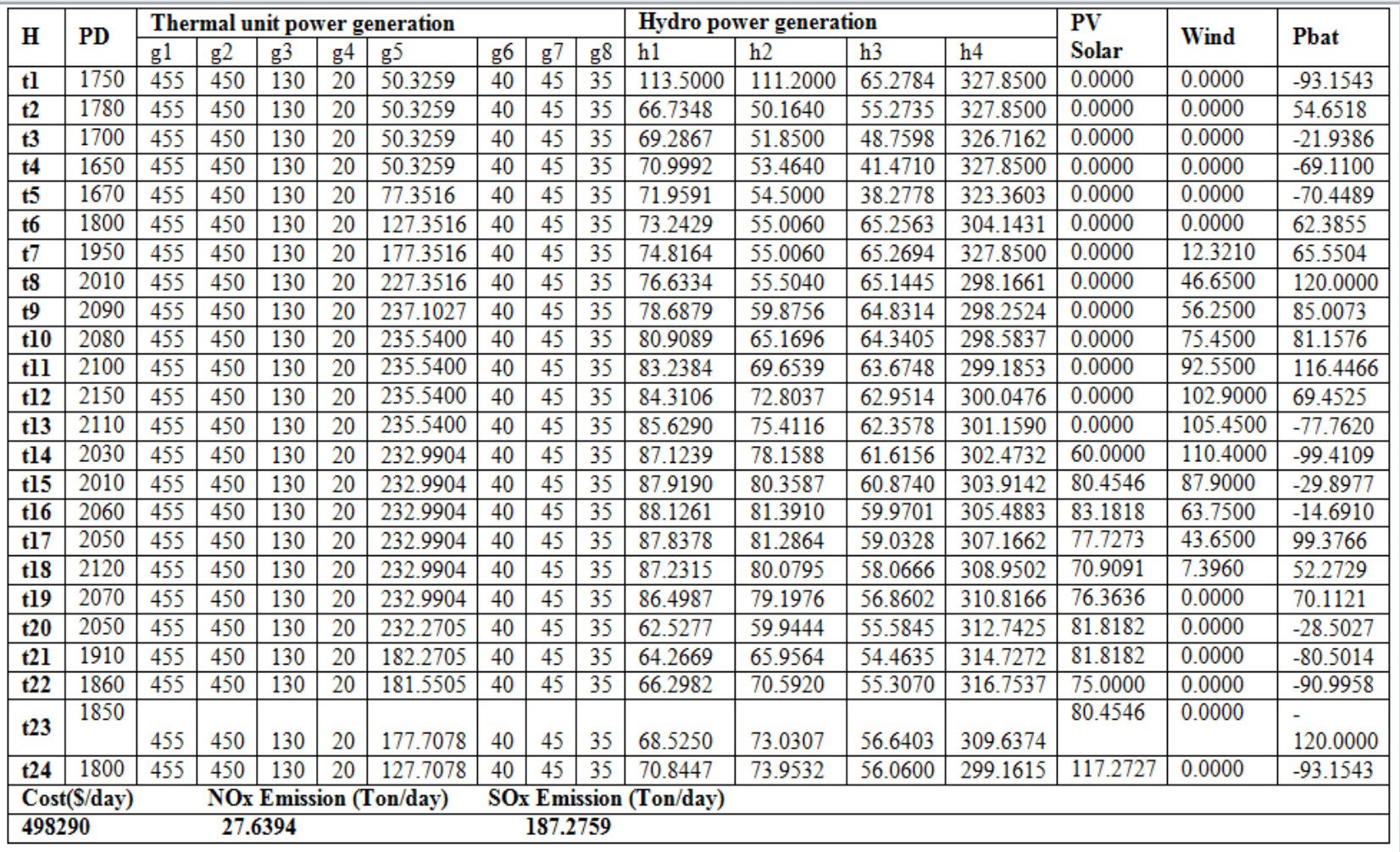

The convergence of objective functions of all cases with iterations using MOPSO algorithm is depicted by Figure.1. It shows that MOPSO converges faster and has got a superior performance. The curve has almost stopped declining since about the 550 th Iterations, it's declines gradually, and it finally achieves the lowest level.
Figure 2 (a)-(d) illustrated pareto front and best solution for all case, respectively. It is able to obtain the optimal pareto-front of the all solution, that are well distributed in the search space.. The cost and emission objectives are actually contradictory and non commensurate in nature. In such problems there is no single optimal 
solution to a problem. The best solution out of the Pareto-optimal solutions is a tedious task. In this paper, a fuzzy ranking method is used for finding the best compromise solution.

Table 2. Best scheduling and dispatching of generation (MW) for case 2 of test system

\begin{tabular}{|c|c|c|c|c|c|c|c|c|c|c|c|c|c|c|c|c|}
\hline \multirow{2}{*}{$\mathbf{H}$} & \multirow{2}{*}{ PD } & \multicolumn{8}{|c|}{ Thermal unit power generation } & \multicolumn{4}{|c|}{ Hydro power generation } & \multirow{2}{*}{ PV Solar } & \multirow{2}{*}{ Wind } & \multirow{2}{*}{ Pbat } \\
\hline & & g1 & g2 & $\mathrm{g} 3$ & $\mathrm{~g} 4$ & g5 & g6 & g7 & g8 & h1 & $\mathrm{h} 2$ & h3 & $\mathrm{h} 4$ & & & \\
\hline tl & 1750 & 299.4152 & 299.4149 & 130 & 20 & 25 & 460 & 45 & 35 & 90.6980 & 66.2000 & 65.2784 & 249.37 & 0.0000 & 0.0000 & -35.3766 \\
\hline t2 & 1780 & 299.3701 & 299.3696 & 130 & 20 & 25 & 460 & 45 & 35 & 75.4410 & 49.0000 & 58.8221 & 248.6058 & 0.0000 & 0.0000 & 34.3914 \\
\hline t3 & 1700 & 299.3939 & 299.3937 & 130 & 20 & 25 & 460 & 45 & 35 & 75.7683 & 50.1640 & 50.4206 & 249.3700 & 0.0000 & 0.0000 & -39.5104 \\
\hline t4 & 1650 & 299.3664 & 299.3661 & 130 & 20 & 25 & 460 & 45 & 35 & 76.3816 & 51.2960 & 49.2708 & 249.3700 & 0.0000 & 0.0000 & -90.0509 \\
\hline t5 & 1670 & 299.3782 & 299.3782 & 130 & 20 & 25 & 460 & 45 & 35 & 76.5683 & 52.9340 & 46.8249 & 249.3700 & 0.0000 & 0.0000 & -69.4536 \\
\hline t6 & 1800 & 326.7483 & 326.7486 & 130 & 20 & 25 & 460 & 45 & 35 & 76.4328 & 57.8209 & 47.8794 & 249.3700 & 0.0000 & 0.0000 & 50.1854 \\
\hline t7 & 1950 & 367.2091 & 367.208 & 130 & 20 & 25 & 460 & 45 & 35 & 75.8246 & 62.0828 & 48.2573 & 251.9118 & 0.0000 & 12.3210 & 67.0004 \\
\hline t8 & 2010 & 367.1876 & 367.1877 & 130 & 20 & 25 & 460 & 45 & 35 & 75.5910 & 65.1359 & 48.9469 & 257.3005 & 0.0000 & 46.6500 & 120.0000 \\
\hline t9 & 2090 & 371.8969 & 371.9005 & 130 & 20 & 25 & 460 & 45 & 35 & 75.8431 & 67.1673 & 49.3353 & 262.6068 & 0.0000 & 56.2500 & 92.1174 \\
\hline t10 & 2080 & 367.2086 & 367.2091 & 130 & 20 & 25 & 460 & 45 & 35 & 76.5029 & 69.4702 & 49.3441 & 267.6977 & 0.0000 & 75.4500 & 86.6361 \\
\hline t11 & 2100 & 367.2092 & 367.2089 & 130 & 20 & 25 & 460 & 45 & 35 & 77.5578 & 72.1253 & 49.0023 & 272.7105 & 0.0000 & 92.5500 & 117.5388 \\
\hline t12 & 2150 & 367.2101 & 367.2094 & 130 & 20 & 25 & 460 & 45 & 35 & 78.8815 & 75.1026 & 48.6017 & 277.5559 & 0.0000 & 102.9000 & 66.5220 \\
\hline t13 & 2110 & 367.2152 & 367.2173 & 130 & 20 & 25 & 460 & 45 & 35 & 80.5094 & 77.7968 & 48.1313 & 282.1581 & 0.0000 & 105.4500 & -66.5931 \\
\hline t14 & 2030 & 358.2016 & 358.2009 & 130 & 20 & 25 & 460 & 45 & 35 & 80.8834 & 79.4939 & 47.9019 & 286.5115 & 60.0000 & 110.4000 & -91.2680 \\
\hline t15 & 2010 & 358.1998 & 358.2007 & 130 & 20 & 25 & 460 & 45 & 35 & 81.5705 & 80.9626 & 48.2393 & 290.7405 & 80.4546 & 87.9000 & -27.0551 \\
\hline t16 & 2060 & 358.1987 & 358.1995 & 130 & 20 & 25 & 460 & 45 & 35 & 82.7148 & 82.9763 & 48.2128 & 294.8213 & 83.1818 & 63.7500 & -17.7005 \\
\hline t17 & 2050 & 358.1982 & 358.1957 & 130 & 20 & 25 & 460 & 45 & 35 & 83.4501 & 84.7835 & 48.1456 & 298.5500 & 77.7273 & 43.6500 & 83.5728 \\
\hline t18 & 2120 & 358.2016 & 358.2016 & 130 & 20 & 25 & 460 & 45 & 35 & 83.8692 & 85.5297 & 47.7266 & 309.5935 & 70.9091 & 7.3960 & 37.5859 \\
\hline t19 & 2070 & 358.2074 & 358.2069 & 130 & 20 & 25 & 460 & 45 & 35 & 83.0744 & 84.2795 & 46.7762 & 310.5062 & 76.3636 & 0.0000 & 81.4581 \\
\hline t20 & 2050 & 358.2058 & 358.2047 & 130 & 20 & 25 & 460 & 45 & 35 & 54.7570 & 49.1257 & 47.6331 & 303.7974 & 81.8182 & 0.0000 & -23.3769 \\
\hline t21 & 1910 & 345.8139 & 345.8121 & 130 & 20 & 25 & 460 & 45 & 35 & 54.6168 & 51.5132 & 49.7135 & 289.0892 & 81.8182 & 0.0000 & -56.6231 \\
\hline$t 22$ & 1860 & 345.8119 & 345.8112 & 130 & 20 & 25 & 460 & 45 & 35 & 54.7050 & 60.0952 & 51.9174 & 268.2824 & 75.0000 & 0.0000 & -120.0000 \\
\hline$t 23$ & 1850 & 343.1922 & 343.1922 & 130 & 20 & 25 & 460 & 45 & 35 & 105.9562 & 80.9790 & 56.6134 & 244.6124 & 80.4546 & 0.0000 & -120.0000 \\
\hline$t 24$ & 1800 & 268.6012 & 268.6008 & 130 & 20 & 25 & 460 & 45 & 35 & 107.0200 & 80.9500 & 59.0053 & 303.5500 & 117.2727 & 0.0000 & -35.3766 \\
\hline \multicolumn{17}{|c|}{ Cost(\$/day) } \\
\hline \multicolumn{17}{|c|}{537240} \\
\hline
\end{tabular}

Table 3. Best scheduling and dispatching of generation (MW) for case 3 of test system

\begin{tabular}{|c|c|c|c|c|c|c|c|c|c|c|c|c|c|c|c|c|}
\hline \multirow{2}{*}{ H } & \multirow{2}{*}{ PD } & \multicolumn{8}{|c|}{ Thermal unit power generation } & \multicolumn{4}{|c|}{ Hydro power generation } & \multirow{2}{*}{$\begin{array}{l}\text { PV } \\
\text { Solar }\end{array}$} & \multirow{2}{*}{ Wind } & \multirow{2}{*}{ Pbat } \\
\hline & & g1 & g2 & g3 & g4 & g5 & g6 & g7 & g8 & h1 & $\mathrm{h} 2$ & h3 & h4 & & & \\
\hline tl & 1750 & 50 & 50 & 20 & 130.0000 & 470 & 40 & 223.9319 & 300 & 94.3455 & 67.0229 & 65.2784 & 249.3700 & 0.0000 & 0.0000 & -9.9487 \\
\hline $\mathbf{t 2}$ & 1780 & 50 & 50 & 20 & 130.0000 & 470 & 40 & 223.9319 & 300 & 78.2380 & 50.1024 & 46.6694 & 249.3700 & 0.0000 & 0.0000 & 71.6884 \\
\hline t3 & 1700 & 50 & 50 & 20 & 130.0000 & 470 & 40 & 240.8275 & 300 & 78.2710 & 51.2361 & 45.4993 & 249.3700 & 0.0000 & 0.0000 & -25.2038 \\
\hline t4 & 1650 & 50 & 50 & 20 & 130.0000 & 470 & 40 & 270.8275 & 300 & 77.8388 & 55.3557 & 42.4695 & 249.3700 & 0.0000 & 0.0000 & -105.8614 \\
\hline t5 & 1670 & 50 & 50 & 20 & 130.0000 & 470 & 40 & 300.8275 & 300 & 76.9846 & 59.3841 & 38.6750 & 247.5864 & 0.0000 & 0.0000 & -113.4575 \\
\hline t6 & 1800 & 50 & 50 & 20 & 130.0000 & 470 & 40 & 330.8275 & 300 & 75.7287 & 62.3106 & 38.9801 & 249.3700 & & 0.0000 & -17.2169 \\
\hline t7 & 1950 & 50 & 50 & 20 & 130.0000 & 470 & 40 & 360.8275 & 300 & 75.1310 & 64.3435 & 39.9902 & 249.3700 & 0.0000 & 12.3210 & 88.0169 \\
\hline t8 & 2010 & 50 & 50 & 20 & 130.0000 & 470 & 40 & 390.8275 & 300 & 75.1255 & 65.5710 & 40.5985 & 249.3700 & 0.0000 & 46.6500 & 81.8576 \\
\hline t9 & 2090 & 50 & 50 & 20 & 130.0000 & 470 & 40 & 420.8275 & 300 & 75.6783 & 67.3573 & 40.9279 & 249.3700 & 0.0000 & 56.2500 & 119.5891 \\
\hline t10 & 2080 & 50 & 50 & 20 & 130.0000 & 470 & 40 & 450.8275 & 300 & 76.7489 & 69.6806 & 40.9875 & 249.3700 & 0.0000 & 75.4500 & 56.9355 \\
\hline t11 & 2100 & 50 & 50 & 20 & 130.0000 & 470 & 40 & 465.0000 & 300 & 78.2267 & 72.4363 & 41.1341 & 249.3700 & 0.0000 & 92.5500 & 41.2829 \\
\hline t12 & 2150 & 50 & 50 & 20 & 130.0000 & 470 & 40 & 465.0000 & 300 & 80.0093 & 74.9288 & 41.3779 & 249.3700 & 0.0000 & 102.9000 & 76.4139 \\
\hline t13 & 2110 & 50 & 50 & 20 & 130.0000 & 470 & 40 & 465.0000 & 300 & 80.6720 & 76.5086 & 42.0951 & 249.3700 & 0.0000 & 105.4500 & 30.9042 \\
\hline t14 & 2030 & 50 & 50 & 20 & 130.0000 & 470 & 40 & 465.0000 & 300 & 81.7382 & 77.8510 & 43.6436 & 249.3700 & 60.0000 & 110.4000 & -118.0028 \\
\hline t15 & 2010 & 50 & 50 & 20 & 130.0000 & 470 & 40 & 444.6615 & 300 & 83.1003 & 79.5671 & 44.9466 & 249.3700 & 80.4546 & 87.9000 & -120.0000 \\
\hline t16 & 2060 & 50 & 50 & 20 & 130.0000 & 470 & 40 & 465.0000 & 300 & 83.7240 & 80.7233 & 46.3704 & 249.3700 & 83.1818 & 63.7500 & -72.1194 \\
\hline t17 & 2050 & 50 & 50 & 20 & 130.0000 & 470 & 40 & 464.2305 & 300 & 84.0245 & 80.8066 & 47.5888 & 249.3700 & 77.7273 & 43.6500 & -57.3977 \\
\hline t18 & 2120 & 50 & 50 & 20 & 130.0000 & 470 & 40 & 434.2305 & 300 & 84.1386 & 79.5897 & 48.9071 & 252.216 & 70.9091 & 7.3960 & 82.6129 \\
\hline t19 & 2070 & 50 & 50 & 20 & 130.0000 & 470 & 40 & 404.2305 & 300 & 84.1728 & 76.6433 & 50.2359 & 257.4446 & 76.3636 & 0.0000 & 60.9093 \\
\hline$t 20$ & 2050 & 50 & 50 & 20 & 130.0000 & 470 & 40 & 374.2305 & 300 & 54.1800 & 36.3016 & 51.2277 & 272.2420 & 81.8182 & 0.0000 & 120.0000 \\
\hline$t 21$ & 1910 & 50 & 50 & 20 & 130.0000 & 470 & 40 & 344.2305 & 300 & 54.3018 & 37.7706 & 51.7893 & 271.3174 & 81.8182 & 0.0000 & 8.7722 \\
\hline t22 & 1860 & 50 & 50 & 20 & 130.0000 & 470 & 40 & 314.2305 & 300 & 54.5202 & 39.9140 & 53.5520 & 278.4032 & 75.0000 & 0.0000 & -15.6199 \\
\hline t23 & 1850 & 50 & 50 & 20 & & 470 & 40 & & 270 & & & & & 80.4546 & 0.0000 & \\
\hline t24 & 1800 & 50 & 50 & 20 & 127.9714 & 470 & 40 & 254.2305 & 240 & 107.0200 & 80.9500 & 59.0053 & 303.5500 & 117.2727 & 0.0000 & -120.0000 \\
\hline & & & & & & & & & & (Ton/day) & & & n/day) & & & \\
\hline & & & & & & & 800 & & & 9267 & & 180.83 & & & & \\
\hline
\end{tabular}

Economic, NOx emission, SOx emission dispatch and combined problem objectives are minimized using MOPSO. Hydro, wind, PV solar and thermal production from economic optimization, NOx emission optimization, SOx emission optimization and combined problem are given in tables $1-4$, respectively. The optimal hourly plant discharges of four hydro power plants from economic optimization, NOx emission optimization, SOx emission optimization and combined problem are listed in Figure.3 (a)-(d) respectively. Figure 4 (a)-(d) give the reservoir storage volumes of four hydro plants from economic minimization, NOx emission minimization, SOx emission 
minimization and combined problem respectively. PV solar and wind power production of total fuel cost for the scheduled day is same for cost optimization, NOx emission optimization, SOx emission optimization and combined problem.

Table 4. Best scheduling and dispatching of generation (MW) for case 4 of test system

\begin{tabular}{|c|c|c|c|c|c|c|c|c|c|c|c|c|c|c|c|c|}
\hline \multirow{2}{*}{$\mathbf{H}$} & \multirow{2}{*}{ PD } & \multicolumn{8}{|c|}{ Thermal unit power generation } & \multicolumn{4}{|c|}{ Hydro power generation } & \multirow{2}{*}{$\begin{array}{c}\text { PV } \\
\text { Solar }\end{array}$} & \multirow{2}{*}{ Wind } & \multirow{2}{*}{ Pbat } \\
\hline & & g1 & g2 & g3 & $\mathrm{g} 4$ & g5 & g6 & g7 & g8 & h1 & h2 & h3 & $\mathrm{h} 4$ & & & \\
\hline tl & 1750 & 236.6894 & 265.8425 & 130 & 20 & 25 & 460 & 45 & 35 & 113.5000 & 111.200 & 65.2784 & 327.8500 & 0.0000 & 0.0000 & -85.3603 \\
\hline t2 & 1780 & 236.6894 & 265.8425 & 130 & 20 & 25 & 460 & 45 & 35 & 99.2594 & 90.7390 & 53.8279 & 327.8500 & 0.0000 & 0.0000 & -9.2082 \\
\hline t3 & 1700 & 236.6894 & 265.8425 & 130 & 20 & 25 & 460 & 45 & 35 & 65.0664 & 52.3960 & 46.4538 & 327.8500 & 0.0000 & 0.0000 & -9.2980 \\
\hline t4 & 1650 & 236.6894 & 265.8425 & 130 & 20 & 25 & 460 & 45 & 35 & 68.6134 & 53.4640 & 42.2005 & 327.8500 & 0.0000 & 0.0000 & -59.6598 \\
\hline t5 & 1670 & 236.6894 & 265.8425 & 130 & 20 & 25 & 460 & 45 & 35 & 69.9897 & 53.9860 & 38.6750 & 326.2912 & 0.0000 & 0.0000 & -36.4737 \\
\hline t6 & 1800 & 275.8046 & 305.0018 & 130 & 20 & 25 & 460 & 45 & 35 & 71.7493 & 53.9860 & 64.7960 & 313.6622 & 0.0000 & 0.0000 & 0.0000 \\
\hline t7 & 1950 & 327.3480 & 356.6032 & 130 & 20 & 25 & 460 & 45 & 35 & 73.7456 & 54.5000 & 65.2563 & 297.5608 & 0.0000 & 12.3210 & 47.6651 \\
\hline t8 & 2010 & 327.3480 & 356.6032 & 130 & 20 & 25 & 460 & 45 & 35 & 75.8920 & 55.3712 & 65.1999 & 327.8500 & 0.0000 & 46.6500 & 40.0857 \\
\hline t10 & 2080 & 327.3480 & 356.6032 & 130 & 20 & 25 & 460 & 45 & 35 & 80.5872 & 63.281 & 64.0642 & 327.8500 & 0.0000 & 75.4500 & 69.8163 \\
\hline t11 & 2100 & 327.3480 & 356.6032 & 130 & 20 & 25 & 460 & 45 & 35 & 81.6939 & 66.6819 & 63.1145 & 312.6642 & 0.0000 & 92.5500 & 84.3444 \\
\hline t12 & 2150 & 327.7906 & 357.0463 & 130 & 20 & 25 & 460 & 45 & 35 & 82.8588 & 69.3762 & 62.1669 & 312.8612 & 0.0000 & 102.9000 & 120.0000 \\
\hline t13 & 2110 & 327.3480 & 356.6032 & 130 & 20 & 25 & 460 & 45 & 35 & 84.1791 & 72.1722 & 60.8847 & 313.3428 & 0.0000 & 105.4500 & 75.0199 \\
\hline t14 & 2030 & 327.3480 & 356.6032 & 130 & 20 & 25 & 460 & 45 & 35 & 84.7666 & 74.4896 & 59.4106 & 314.0983 & 60.0000 & 110.4000 & -72.1163 \\
\hline t15 & 2010 & 327.3480 & 356.6032 & 130 & 20 & 25 & 460 & 45 & 35 & 84.6215 & 75.6597 & 57.5969 & 315.0852 & 80.4546 & 87.9000 & -90.2690 \\
\hline t16 & 2060 & 327.3480 & 356.6032 & 130 & 20 & 25 & 460 & 45 & 35 & 84.1039 & 76.0277 & 55.5740 & 316.2361 & 83.1818 & 63.7500 & -17.8246 \\
\hline t17 & 2050 & 327.3480 & 356.6032 & 130 & 20 & 25 & 460 & 45 & 35 & 83.3398 & 75.5839 & 53.3215 & 317.5573 & 77.7273 & 43.6500 & -0.1310 \\
\hline t18 & 2120 & 327.3480 & 356.6032 & 130 & 20 & 25 & 460 & 45 & 35 & 82.4163 & 75.6471 & 50.5341 & 319.0215 & 70.9091 & 7.3960 & 115.1247 \\
\hline$t 20$ & 2050 & 327.3480 & 356.6032 & 130 & 20 & 25 & 460 & 45 & 35 & 71.3426 & 70.2885 & 49.5071 & 322.3001 & 81.8182 & 0.0000 & 55.7923 \\
\hline t21 & 1910 & 303.8319 & 333.0607 & 130 & 20 & 25 & 460 & 45 & 35 & 73.1550 & 73.6817 & 51.5782 & 324.0285 & 81.8182 & 0.0000 & -46.1542 \\
\hline$t 22$ & 1860 & 303.8319 & 333.0607 & 130 & 20 & 25 & 460 & 45 & 35 & 74.8908 & 74.7611 & 52.6030 & 307.9488 & 75.0000 & 0.0000 & -77.0964 \\
\hline t23 & 1850 & 303.8319 & 333.0607 & 130 & 20 & 25 & 460 & 45 & 35 & 76.9298 & 74.2461 & 53.0680 & 290.1583 & 80.4546 & 0.0000 & -76.7494 \\
\hline t24 & 1800 & 271.5165 & 300.7089 & 130 & 20 & 25 & 460 & 45 & 35 & 78.0026 & 77.6232 & 56.3262 & 303.5500 & 117.2727 & 0.0000 & -120.000 \\
\hline \multicolumn{17}{|c|}{ Cost $(\$ /$ day $)$} \\
\hline
\end{tabular}

Table 5. Summary results for the test system.

\begin{tabular}{|c|c|c|c|c|}
\hline \multicolumn{2}{|c|}{ Problem dispatch } & $\begin{array}{c}\text { Cost } \\
\text { (\$/day) }\end{array}$ & $\begin{array}{c}\text { NOx Emission } \\
\text { (Ton/day) }\end{array}$ & $\begin{array}{c}\text { SOx Emission } \\
\text { (Ton/day) }\end{array}$ \\
\hline \multirow{2}{*}{ Economic } & Proposed MOPSO & 498290 & 27.6394 & 187.2759 \\
\hline & NSGA-II [4] & 567491 & 36.0226 & 194.4046 \\
\hline \multirow{2}{*}{ NOx emission } & Proposed MOPSO & 537240 & 25.8175 & 195.4521 \\
\hline & NSGA-II [4] & 582711 & 35.0342 & 196.0739 \\
\hline \multirow{2}{*}{ Sox emission } & Proposed MOPSO & 572230 & 44.1082 & 177.8355 \\
\hline & NSGA-II [4] & 585235 & 37.7592 & 192.8073 \\
\hline \multirow{4}{*}{$\begin{array}{c}\text { Combined } \\
\text { Prolem }\end{array}$} & \multirow{2}{*}{ Proposed MOPSO } & 517530 & 25.2596 & 188.8443 \\
\hline & & \multicolumn{3}{|c|}{ Total cost : 7140400 (Ton/day) } \\
\hline & \multirow{2}{*}{ NSGA-II [4] } & 575566 & 35.9916 & 194.4635 \\
\hline & & \multicolumn{3}{|c|}{ Total cost : ----- (Ton/day) } \\
\hline
\end{tabular}

Respect the ramp rate constraint equation (5) to solve DEED with the all cases test systems, Figure 5 (a)-(d) show the result.

\section{CONCLUSIONS AND PERSPECTIVES}

In this paper, MOPSO applied for CDEEP the combined problem of economical distribution of dynamic emissions with transmission power loss and VPE. To cope with this non-convex problem, linear approximation is employed to transmission power loss and the non-smooth total fuel cost function, and therefore the classical CEED problem is converted to the MOPSO problem. The property of convergence, the computation efficiency and the economic effect of emission are well demonstrated in our present paper. This allows us to say that this MOPSO optimization algorithm is an efficient and robust method which is capable of solving these examples of nonlinear multi-objective optimization linked to electrical networks incorporating renewable energy, hydro and ESS operation and multi area are a future work.

\section{ACKNOWLEDGEMENTS}

This work is a part of the Research in Electrical Engineering department of ENIS Sfax UniversityTunisia.

\section{REFERENCES}

D.P. Kothari, J.S. Dhillon, Power Optimization, PHI Learning Pvt. Ltd., 2004

Elaiwa, A.M., Xia, X., Shehata, A.M., 2013. Hybrid DESQP and hybrid PSO-SQP methods for solving dynamic economic emission dispatch.

G.B. Sheble D.C. Walter, , IEEE Trans. 8 (August) (1993) 1325-1332.

George W. , Kang Li, Irwin , Hongyun Zhang Qun Niu, , An efficient harmony search with new pitch adjustment for DED, Energy 65 (2014) 25-43. 
IEEE Trans. Power Syst ,IEEE Current Operating Working Group,. 10 (1995) 647-653.

J. Hetzer, D.C. Yu, K. Bhattarai, IEEE Trans.. 23 (June (no. 2)) (2008) 603-611.

J. Kennedy and R. Eberhart, “ PSO,” Proc. IEEE Int. Conf. Neural Networks, 1995, Vol. IV, pp. 1942-1948.

J.W. Lamont, E.V. Obessis, IEEE Trans. Power Syst. 10 (May (no. 2)) (1995) 941- 947.

K N. Chakraborty, M. Basu, .K. Mandal,. PSO technique based short-term hydrothermal scheduling. 8 (2008) 1392-1399. doi:10.1016/j.asoc.2007.10.006

K.K. Mandal, N.Chakraborty "Differential evolution technique- economic generation scheduling of hydrothermal”. Electric Research 78 (2008) 19721979.

K.Y. Lee and M.A., Modern heuristics techniques with applications to power systems. IEEE Engineering Society (02TP160), 2002.

L. Lak, S. Sub, IEE Proc. Gener. Transm. Distrib. 153 (November (No. 6)) (2006) 693-700.

M. Basu, Economic environmental dispatch of solar- wind-hydro-thermal power system. Renewable Energy Focus Volume 30, Number 00 September 2019. p 107122. https://doi.org/10.1016/j.ref.2019.04.002

M. Basu, Int. J. Electr.Optimal dispatch for DEEP. 58 (June) (2014) 91-100.

Ruey-Hsun Liang and Jian-Hao Liao, IEEE Trans (November (No. 4)) (2007) 1665-1674.

Ruey-Hsun Liang and Jian-Hao Liao, IEEE Trans. (November (No. 4)) (2007) 1665-1674.

Suresh K. Damodaran and T. K. Sunil Kumar 2. HydroThermal-Wind Generation Scheduling Considering Economic and Environmental Factors Using Heuristic Algorithms. Energies 2018, 11, 353; doi: 10.3390/ en 11020353.

Tapaswi, S., Tripathi, A., Pandit, N2012. An improved bacterial foraging algorithm for combined static/DEE dispatch. Soft Comput. 12 (11), 3500-3513

Xiaohui Yuan et all. An extended NSGA-III for solution MO hydro-thermal-wind scheduling wind power fuel cost. Energy and Management 96 (2015) 568-578. http://dx.doi.org/10.1016/j.enconman.2015.03.009. 